\title{
SCIENCE AND THE BRITISH MEDICAL ASSOCIATION.
}

The first of the two chief objects set out in the Memorandum of Association of the British Medical Association is the promotion of the medical and allied sciences, and it may fairly be said that pursuit of the second, namely the maintenance of the honour and interests of the medical profession, directly contributes to the attainment of the first. In the pursuit of its scientific activities, details of some of which are given below, the Association spends each year a considerable portion of its income.

Foremost amongst these activities is the publication of the British Medical Journal, with a weekly circulation of 43,250 copies. The Journal serves as a comprehensive record of current developments and a forum for discussion in every field of medical science and professional organization in this country. The Association also publishes, in its Archives of Disease in Childhood, a quarterly review of current thought in this branch. A new quarterly publication, the British Heart Journal, deals with the study of Cardiology and the Circulation. Apart from its periodical publications, the Association from time to time undertakes investigations, whether through special Committees or by the promotion of collective research, and publishes reports on the results. Recent examples of such reports are those on psycho-analysis, tests for drunkenness, mental deficiency, nutrition, fractures, relation of alcohol to road accidents, medical education, physical education, miners' nystagmus, etc. Copies of such reports can be obtained on application to the Secretary, B.M.A. House, Tavistock Square, W.C.1. Notices of investigations actually in progress are published from time to time in the British Medical Journal.

In the organization of the Scientific Sections at its Annual Meetings, the Association provides an unrivalled opportunity for discussion of new methods and old difficulties, not only within the confines of small groups of specialists but between specialists and the main body of the profession. British Medical Association Lectures in the Divisions and Branches afford another means of contact between the specialist and the general practitioner, and the regular clinical meetings and discussions arranged by many of the Divisions and Branches are an outstanding feature of the local life of the Association.

For many years the Association has offered Scholarships and Grants to the amount of $£ 1,000$ annually to enable approved workers to prosecute research in subjects of their own choice. Besides these annual grants, a number of special Prizes are awarded by the Association, e.g. the Stewart Prize for work on epidemic disease, the Middlemore Prize for work on a prescribed subject in some department of ophthalmic medicine or surgery, the Katherine Bishop Harman Prize for research in the disorders incident to maternity. These prizes are awarded periodically, and notice of pending awards is published in the British Medical Journal and elsewhere. In addition, the Association awards annually the Sir Charles Hastings Clinical Prize for systematic observation, research and record in general practice. Particulars of all prizes, scholarships and grants may be obtained on application to the Secretary.

Members are entitled to use the Reading Room at the House of the Association, with its files of periodical medical literature, British and foreign, the Reference Library, and the Circulating Library. The Librarian is always ready to answer enquiries by members, whether personal or postal, and to supply references. 